\title{
A ECONOMIA MORAL DO TURISMO
}

\author{
Dean MacCannell \\ Departamento de Design Ambiental, Universidade da California, Estados Unidos da América
}

\begin{abstract}
Resumo
Neste artigo, sugiro que a indústria do turismo mundial está mobilizada em torno de um núcleo, a atração turística, que está afastada e protegida do intercâmbio económico. Se o turismo é, de facto, a maior indústria do mundo, é por causa e não a despeito da separação da sua principal estrutura motivacional e moral do mercado. Aqui exploro as implicações do facto de que o sistema global de atrações turísticas é uma enorme coleção de "bens gratuitos" democráticos, abertos e disponíveis para todos verem. A indústria do turismo depende desta oferta interminável de atrações de livre acesso, mantidas por governos, ONG e/ou simplesmente existentes na sociedade e na natureza. A indústria do turismo mundial só pode prosperar se a sua estrutura moral e motivacional permanecer isolada das transações do mercado. O Taj Mahal, a Torre Eiffel, o Partenon, o Grand Canyon, a Estátua da Liberdade, as Montanhas Karakorum, etc., não estão à venda. Mais de mil milhões de turistas gastam 1,5 biliões de dólares por ano para viajar internacionalmente e ver coisas que não podem comprar ou ter no sentido material; que ninguém, por mais rico que seja, pode comprar; que muitas vezes nem conseguem tocar. A enormidade do turismo hoje é possível apenas porque as forças causais que estão no coração da economia do turismo são inteiramente imaginárias e simbólicas. Na sua essência, a economia turística é menos económica do que fenomenológica. E o principal impulso do turismo, a sua motivação mais profunda, não é materialista, mas democrática. O overtourism (excesso de turismo) resulta da própria indústria que explora agressivamente o facto de que não implica matérias-primas, não necessita de desenvolver cadeias de fornecimento, não precisa de fábricas e não se envolve em qualquer conceção, fabrico, montagem ou distribuição. O consumidor trabalha de graça, na realidade, paga para fazer o trabalho do turismo e torna-se o produto. Estas eficiências neoliberais levam ao overtourism. $\mathrm{O}$ overtourism pode ser facilmente controlado ao nível local.
\end{abstract}

\section{PaLAVRAS-Chave}

turista global pré-moderno e moderno; experiência turística; compacto turístico moderno; pacotes turísticos; excesso de turismo

\section{THE MORAL ECONOMY OF TOURISM}

\begin{abstract}
In this article I suggest that the global tourism industry is deployed around a nucleus, the tourist attraction, that is removed and protected from economic exchange. If tourism is, indeed, the world's largest industry it is because, and not in spite of the separation of its primary motivational and moral structure from the marketplace. I explore the implications of the fact that the global system of tourist attractions is a massive collection of democratic "free goods" open and available for all to see. The tourist industry depends on this endless supply of free access attractions maintained by governments, NGOs, and/or simply existing in society and nature. The global tourism industry can thrive only if its moral and motivational structure remains insulated from market transactions. The Taj Mahal, the Eiffel Tower, the Parthenon, the Grand Canyon,
\end{abstract}


the Statue of Liberty, the Karakorum Mountains, etc. are not for sale. Over a billion tourists spend $\$ 1,5$ trillion annually to travel internationally to things they cannot buy or have in any material sense; that no one no matter how wealthy can buy; often that they cannot even touch. The enormity of tourism today is possible only because the causal forces at the heart of the tourism economy are entirely imaginary and symbolic. At its core, the tourist economy is less economical than phenomenological. And the primary tourist drive, its deepest motivation, is not materialistic but democratic. Overtourism results from the industry aggressively exploiting the fact that it requires no raw materials, need not develop supply chains, needs no factories, and engages in no design, manufacture, assembly or distribution. The consumer works for free, indeed, pays to do the work of tourism, and becomes the product. These neoliberal efficiencies lead to overtourism. Overtourism can easily be controlled at the local level.

\author{
KeYwORDS \\ premodern and modern global tourist; tourist experience; modern \\ tourist compact; packaged tours; overtourism
}

O mundo está tão cheio de várias coisas...

Robert Louis Stevenson'

\title{
TURISMO PRÉ-MODERNO
}

O poeta grego do século XX e vencedor do Nobel, George Seferis (1997, p. 92), diz-nos que já quando Plutarco visitou Delfos, fê-lo como turista: “[na] época de Plutarco... o templo tornou-se um local turístico com guias organizados a mostrar os espaços às multidões". Seferis rapidamente nos adverte a não supor que Plutarco e os seus companheiros turistas eram semelhantes aos turistas de hoje. Ele afirmou que as primeiras multidões de turistas partilhavam um sistema de crenças, uma fé. Era uma fé frágil e enfraquecida mas, não obstante, uma visão comum do mundo que os unia. Seferis escreve, "hoje a fé comum perdeu-se e as pessoas que vêm têm cada uma mitos pessoais diferentes" (1997, p. 92). Ele tem razão, claro: hoje em dia, cada turista traz o seu próprio mito pessoal para o local e sai com a sua própria impressão única. Mas o que permanece constante agora, tal como na época de Plutarco, é que os turistas continuam a visitar Delfos e todas as outras grandes atrações mundiais. ${ }^{2}$

O turismo é comprovadamente ainda mais antigo do que a visita de Plutarco a Delfos. Encontro poucas razões para acreditar que o turismo não seja tão antigo quanto a própria humanidade. Alguém que sai de casa apenas para ver o que está mais além, os guias turísticos sob a forma de espíritos guardiões figuram fortemente nos mitos pré-históricos. Toda a literatura revela que sempre houve precursores do nosso tipo de turismo distintamente moderno, tecnologicamente habilitado e contemporâneo. Afinal, o que são Odisseu e Eneias, senão protótipos do tipo de experiência que o turismo moderno

\footnotetext{
' Retirado de https://www.kellscraft.com/childsversel.html

${ }^{2}$ Esta é uma versão revista de um discurso para a reunião anual do International Forum for Economic Research (INFER Fórum Internacional de Investigação em Economia), Atenas, Grécia, 2016.
} 
ambiciona oferecer: viagens de autodescoberta espiritualmente ricas, que resultam de encontros com "alteridade" ou o que eu preferiria designar como "diferença absoluta"?

\section{DEMOCRACIA E O TURISTA MODERNO}

Nem o próprio turismo, nem nenhum dos recentemente designados novos "tipos" de turismo são realmente novos. O turismo sexual, o turismo da morte, o turismo extremo, o turismo médico, etc. têm todos as suas variantes antigas. O que é novo são as maneiras como agora estruturamos a experiência do turista; as dimensões morais, éticas e ideológicas das relações entre os turistas atuais e os povos e os locais que estes vêm ver. O primeiro e ainda o melhor relato da base renovada para a nossa "fé" atual no turismo continua a ser Memoirs of a tourist de Stendhal (1838/1962).

Originalmente publicado em 1838, a obra Memoirs of a tourist continua editada em vários idiomas. Uma maneira rápida de perceber o motivo da sua longevidade e durabilidade é simplesmente abrir o livro aleatoriamente. Uma pequena amostra revela o que é crucial em Memoirs of a tourist: estabelece um catálogo paradigmático de objetos de desejo do turista moderno. O narrador fictício de Stendhal, o Sr. L, é tão entusiasmado por pequenos detalhes locais, como a maneira única como as mulheres de uma aldeia em particular fazem tranças nos seus cabelos, como por monumentos e obras-primas famosas. O Sr. L tem uma voz distinta; a voz de uma pessoa que qualquer um de nós se sentiria feliz por ter como companheiro de viagem. É conhecedor, curioso, liberal, opinativo e generoso nas suas opiniões, mas não insistente; um companheiro de viagem genial que tem sempre algo novo a dizer. Olha avidamente e comenta livremente as muitas maneiras como os lugares, monumentos etc. fazem e não fazem jus à sua fama ou reputação; ou a forma diferente como os vê comparativamente como foram descritos na literatura e nos guias turísticos. Interessa-se especialmente por observar coisas e eventos que não receberam aviso prévio.

A minha cópia de Memoirs of a tourist abre na página 112. O Sr. L está a relatar a sua chegada a Avignon. Vamos segui-lo por um momento. Acabou de ver uma grande formação rochosa de basalto nas margens do Ródano e observou a beleza do rio e dos prados com os Alpes ao fundo. Repara que os trabalhadores de Avignon estão profundamente bronzeados e têm uma "aparência fogosa", e andam com os casacos atirados por cima dos ombros. Visita o túmulo do Papa Inocêncio VI e uma famosa torre e palácio. Vai ao museu municipal recheado de pinturas italianas e desfruta dos jardins do museu. Fica encantado ao ver um rapaz apanhar boleia de uma rapariga num burro. Observa que as ruas são protegidas por lonas durante o tempo quente - "gosto da ideia e da meia-luz que produz" (Stendhal, 1838/1962, p. 120). Não ficou muito impressionado com um objeto que disseram que "precisava de ver": "a indolência natural do viajante fez-me perder uma hora a inspecionar um certo crucifixo de marfim, muito comentado, bastante medíocre..." (Stendhal, 1838/1962, p. 120). Visita uma casa para veteranos de guerra idosos e doentes e deseja-Ihes bom tempo e comida saudável. Um jovem engraxador diz-lhe que um quarto fechado à chave na pensão onde está hospedado foi o local de um famoso assassinato; onde Marshal Brune foi morto em 1815. Contra a vontade do 
proprietário, pede a um funcionário da pensão que lhe mostre. "O chão estava coberto de pulgas. Esta sujidade potenciou o horror do ato sobre o qual eu estava a pensar. $\mathrm{Vi}$ mais claramente a repugnância dos assassinos" (Stendhal, 1838/1962, p. 113).

Stendhal observou a França dos seus dias; mergulhou profundamente nas formas como uma perspetiva democrática, autoconsciente e recém-emergente tenta compreender o que significa ser um turista, um cidadão e, de facto, ser um novo e moderno tipo de ser humano, livre para ser itinerante por opção. O turista de Stendhal não é cego pela sua própria posição social ou identidade. Está ciente de si mesmo enquanto parte da humanidade, enquanto um observador perplexo da humanidade, ligeiramente distanciado. O Sr. $L$ descreve uma noite em que ficou sentado com os funcionários de uma pensão a contar histórias de fantasmas até à uma da manhã. "O céu concedeu-me o talento de me fazer bem-vindo entre os camponeses. Para conseguir isso, não deve falar nem muito nem pouco e, acima de tudo, não deve atingir uma igualdade completa com eles" (Stendhal, 1838/1962, p. 208). A obra Memoirs of a tourist dá-nos uma forma de mapear a curiosidade e o desejo sobre o mundo humano e natural, e uma maneira de estar no mundo, ou seja, como turista. Apenas dez anos depois de o termo ter sido inventado, ensinou-nos que o maior apelo para um "turista" é o envolvimento com toda a gama de diferenças humanas, é procurar instruções a partir de tudo e qualquer coisa que possamos encontrar fora de casa.

Por sua vez, as pessoas e os lugares que Stendhal visita estão interessados em partilhar o que consideram interessante e digno sobre as suas comunidades, a sua região e os seus pensamentos e vidas. Não querem fingir que Stendhal é um deles. Ele é visto por eles como um estranho amigável e interessado. Entram voluntariamente numa troca de histórias através das linhas da diferença humana. Têm orgulho no facto de os considerar dignos do seu interesse. Muitas vezes, são capazes de the revelar segredos que poderiam ser devastadores se ele fosse um deles, mas sentem-se seguros porque ele é um estranho de confiança que partirá em breve.

O tratamento do turismo por Stendhal é a primeira reflexão aprofundada sobre o mesmo, depois do Iluminismo. Em perfeita sincronização com os importantes movimentos políticos da sua época, plantou e criou cuidadosamente as sementes da democracia na atitude do seu turista ideal. O Sr. L estava muito longe de ser um grande turista.

Stendhal nunca insinua que, enquanto turistas, deveríamos gostar de tudo o que vemos, como os escritores de guias turísticos mais recentes às vezes parecem querer fazer. Apenas sugere que nos conectemos com aquilo que estamos a ver, que aceitemos a diferença como interessante e normal, e que digamos algo próprio sobre as nossas observações. Obviamente, assim que alguém descreve as exigências que um novo tipo de mente faz sobre si, outras mentes vão resistir a estas exigências. Stendhal deu-nos, simultaneamente, um turista democrático moderno, paradigmaticamente positivo, e também os fundamentos da sua negação: não. Quero que me digam exatamente o que devo pensar sobre o que estou a ver, de maneira a poder deixar os meus preconceitos intactos. Não era suposto esta viagem ser divertida? Stendhal explicou a atitude que devemos adotar para ser um turista ético moderno. A resistência desenfreada e previsível à perceção stendhaliana é a base dos atuais significados pejorativos de "turista". 


\section{O CONTRATO TURÍSTICO MODERNO}

Não é possível categorizar as coisas que compõem as viagens, ao tentar classificar os objetos de atenção turística por "tipo". Vou apenas propor que chamemos ao grupo de objetos e eventos percebidos pelo turista de Stendhal, e todos nós que surgimos depois, o contrato turístico moderno. Hoje, este contrato abrange um vasto e crescente conjunto simbólico de fenómenos sociais, culturais e naturais, marcados como dignos do olhar do turista. Dignos, porquê? Stendhal deixa isso claro. Tudo o que o Sr. L observa é uma potencial expressão na maior história da espécie humana; o grande abraço democrático de quem somos - todos nós. São partículas das nossas habilidades e sabedoria coletiva; lembretes concretos de atos humanos passados e atuais e dos seus resultados; são literalmente "lições objetivas" que apontam para discernimento e erro, conhecimento quotidiano, perseverança e superação, verdades cantadas e desconhecidas, culpa e inocência, presunção e incerteza, realização e estupidez brilhantes, beleza e fealdade, heroísmo e covardia. Já argumentei (MacCannell, 2011) que o catálogo de temas, valores e relações que podem ser mapeados no sistema global de atrações coincide com as descobertas possibilitadas pela abertura psicanalítica do inconsciente humano. E aqui, quero acrescentar que a inclusão e a abertura do contrato turístico moderno é gémeo do projeto moderno da democracia. Não me refiro à mecânica da democracia - que pode ou não nos representar, que pode ou não exercer o seu voto, etc. - estes têm sempre falhas e devem estar sujeitos a vigilância e melhoria constantes. Refiro-me ao impulso democrático inelutável da alma humana, ao qual todas essas mecânicas devem, em última análise, responder.

\section{A EXPERIÊNCIA DO TURISTA ESTÁ ABERTA A TODOS}

É exatamente aqui que precisamos de prestar muita atenção à estrutura económica do turismo contemporâneo. Se seguirmos o Sr. $L$ dia após dia ou página após página e lermos todas as suas observações peculiares sobre os mais pequenos detalhes da vida local e dos grandes monumentos que encontra pelo caminho, depressa descobrimos que nada daquilo que faz ou observa enquanto turista lhe custa sequer um cêntimo. Paga o transporte, alojamento e refeições, e serviços pessoais (como o engraxador) exatamente como qualquer pessoa que tivesse viajado para os mesmos lugares em negócios. A cada dez páginas aproximadamente, o Sr. L queixa-se amargamente de porteiros mal-intencionados que agarram na sua bagagem e insistem em carregá-la por uma comissão, ou de proprietários de pensões "ávidos por dinheiro" que conspiram para fazê-lo perder o seu autocarro, para que tenha de pagar uma refeição ou uma noite extra. Mas enquanto turista, não paga nada. A maioria das coisas sobre as quais escreve estavam (e ainda estão) ao ar livre, onde qualquer um pode vê-las. Mas, mesmo em lugares onde havia a possibilidade de acesso controlado, entrou gratuitamente. Os museus franceses, incluindo o próprio Louvre, estavam abertos e eram gratuitos ao público, seis dias por semana, até ao século $X X$. 


\section{A MACROECONOMIA DO TURISMO HOJE}

Avancemos rapidamente cento e oitenta anos até aos dias de hoje. Alguns já afirmam que o turismo é agora a maior "indústria" do mundo. Seja essa afirmação verdadeira ou não, o turismo tornou-se claramente um componente muito grande da economia global. Sozinho, o turismo internacional representa agora nove por cento do PIB mundial. Desde 2012 que todos os anos se registam mais de mil milhões de passagens de fronteiras internacionais em regime de lazer que envolvem dormidas. Em 2015, o turismo empregava um em cada onze trabalhadores em todo o mundo. Nos últimos 25 anos, em todas as regiões do planeta, ano após ano, o turismo tem sido o setor económico que mais cresce. Em 2015, o turismo gerou mais de 1,5 biliões de dólares em divisas. Este último dado não inclui receitas para o turismo doméstico que, em países desenvolvidos como os Estados Unidos e o Japão, representam mais do que as receitas estrangeiras.

\section{A MiCROECONOMIA DO CONTRATO TURÍSTICO MODERNO}

Ao nível micro, o contrato turístico moderno coloca entraves à teoria económica clássica. Quando uma consumidora na Califórnia compra um carro fabricado no Japão, não é difícil atribuir razões para a compra: precisa de um carro para se deslocar para o trabalho; o carro antigo está a tornar-se pouco fiável; ou quer mudar para um carro melhor; escolheu o carro japonês porque acredita que tem a melhor relação qualidade/ preço. Agora, considere as decisões que toma enquanto turista. Quando uma turista na Califórnia quer ver Delfos e as outras maravilhas da Grécia e o seu desejo toma conta dela de tal forma que acaba por efetivamente fazer a viagem, não existem razões económicas igualmente claras e simples. Os aspetos práticos do seu dia a dia não serão melhorados quando voltar. Quando tentamos determinar o que é que comprou exatamente, a diferença torna-se nítida e inexplicável. A turista não pode levar (Delfos) para casa e estacioná-la na sua garagem, ou usá-la para ir trabalhar todos os dias até que se desgaste e eventualmente a venda ou troque. A lembrança da sua viagem, tudo o que resta dela, não serve nenhum propósito económico ou prático. Tem zero "valor de uso". Não lhe dará uma promoção no trabalho. E, ao contrário de outras compras de luxo, como diamantes, ouro, peles e Ferraris, as suas memórias não podem ser revendidas em tempos difíceis.

Permitam-me voltar aos parêntesis em torno de Delfos no último parágrafo. Tecnicamente são parêntesis fenomenológicos. Tudo o que a turista pode possuir é a imagem fugaz na sua mente, ou a imagem duradoura nas suas fotografias, dos vários pontos turísticos que viu. O que "comprou" é uma imagem posterior dos locais e dos seus arredores e as suas memórias de ter estado lá, memórias que eventualmente residem apenas na sua consciência e na sua caixa de lembranças, partilhadas com outras pessoas através de trocas simbólicas e não económicas.

Permitam-me também voltar às aspas em torno da palavra "comprou" na frase anterior. Coloquei-as porque nenhum turista paga efetivamente para ver Delfos, pelo 
menos não de uma maneira que seja proporcional ao seu investimento para chegar lá. Fodor's Greece (Fisher, 2012) diz-me que ainda custa o mesmo que na altura em que a Juliet Flower MacCannell e eu o visitámos há vários anos, $10 €$ para entrar no complexo de Delfos, incluindo uma visita ao museu. O contrato turístico de hoje mantém a estrutura essencial que possuía nos dias de Stendhal. A maior parte daquilo que os turistas vêm e experimentam é gratuito ou quase gratuito.

A enorme economia turística mundial é composta por um vasto espetro de bens e serviços, que vão desde o protetor solar comum até às suites absurdamente sublimes em hotéis que custam dez mil euros por noite. Os economistas que se concentram no turismo limitam a sua modelagem à penumbra de bens e serviços que rodeiam e apoiam o ato turístico: receitas de restaurantes, hotéis e transportes. Para começar, nenhum economista jamais abordou a questão de o porquê dos turistas saírem de casa. Alberto Sessa levanta estas diferenças nas primeiras páginas do seu livro inovador, para depois colocá-las imediatamente de parte, por ser impossível os economistas lidarem com elas:

o produto de qualquer outra indústria é... algo tangível, algo que nos impressiona pela natureza imponente da sua construção, as suas cores, as embalagens adotadas. Apenas este tipo de produto parece ter valor económico. (Sessa, 1983, p. 15)

Quase que se desculpa, explicando que irá lidar apenas com fenómenos economicamente terciários, instalações turísticas, hotéis e restaurantes, pacotes pré-pagos, viagens aéreas e o desenvolvimento de infraestruturas que facilitam a deslocação do turista em direção ao seu objetivo. Mas o objetivo, o "destino", é tomado como garantido e permanece fora das suas equações. Outros economistas forneceram alguns modelos do papel e do contributo da gestão de destinos e marketing de destinos, mas parecem referir-se ao planeamento de negócios nos setores da hotelaria e viagens, e não a quaisquer melhorias que possam ser feitas na Mona Lisa para torná-la mais atraente.

O foco dos economistas no espetro dos bens e serviços turísticos é justificado em termos puramente económicos. A nossa turista, que viajou da Califórnia para a Grécia, pagou, no mínimo, vários milhares de dólares em voos, roupa de viagem, seguro de viagem, guias turísticos, máquina fotográfica, taxas de roaming, transporte internacional e local, refeições, alojamento, lembranças e talvez algo exclusivo como visitas guiadas privadas. Mas aquilo que veio ver, aquilo que desencadeou todos estes gastos com a viagem, a própria Delfos, custa $10 €$. A turista "compra" Delfos por $10 € \mathrm{e}$, depois de a "adquirir", não possui ou controla nem uma pequena parte dela, exceto à medida que aparece e desaparece da consciência da sua mente.

É claro que aproveitará o seu investimento na viagem para visitar outros sítios pelos quais também paga uma taxa de entrada simbólica. Ou então nada. E, como Stendhal, levará consigo imagens e memórias adicionais, queridas e desagradáveis de uma panóplia de locais, sons e cheiros que vivenciou gratuitamente. No final, os custos diretos totais das suas queridas lembranças turísticas são uma pequena fração do custo da viagem. Dada a estratificação das amenidades e serviços turísticos, a diferença entre custos diretos e indiretos pode ser surpreendentemente elevada. 
Delfos está certamente tudo menos sozinha no seu papel de indiferente dentro da economia turística. No coração da estrutura motivacional do turismo mundial estão os muitos parentes de Delfos: as pirâmides de Quéops em Gizé, a Grande Muralha, o Grand Canyon, o Monte Cervino, a Torre Eiffel, a Torre de Pisa, a Torre de Londres, a Casa Branca, a Acrópole, a Golden Gate Bridge, a Basílica de Santa Sofia, Angkor Wat, Pão de Açúcar, Teotihuacán, etc. E, claro, o prazer que é simplesmente aproveitar o ambiente em torno de uma caminhada por uma floresta ou de um passeio por um mercado estrangeiro. Não faz qualquer diferença quais os critérios que usamos para colocar uma atração nesta lista. Qualquer lista de atrações no contrato turístico moderno será extremamente extensa e irá sobrepor-se a todas as outras listas. O que as atrações têm em comum é, em primeiro lugar, o facto de atraírem o desejo do turista e colocarem em movimento milhões (agora mais de mil milhões) de turistas. Em segundo lugar, todas podem ser vistas e vivenciadas, em primeira mão, gratuitamente ou por uma taxa simbólica, geralmente menos do que o valor de um bilhete de cinema.

Permitam-me sublinhar mais uma coisa relativamente ao argumento que estou a defender: no coração da economia turística mundial, massiva e crescente, está um tipo de objeto muito especial, definido pelo seu poder de retenção na imaginação do turista e pelo facto de que ele existe para além do alcance do intercâmbio económico. Ninguém pode comprar Delfos. E ninguém pode pagar pelo direito exclusivo de a vivenciar.

$\mathrm{Na}$ medida em que se pensa que uma atração pertence a todos os que habitam a terra, ela não pode pertencer a ninguém. Alguns objetos que são fisicamente mais pequenos e que podem ser incluídos no contrato turístico, nomeadamente a fração de pinturas existentes de antigos mestres que não estão em museus, são comprados e vendidos pelo um por cento mais rico. Bill Gates conseguiu comprar os cadernos de Leonardo da Vinci ao Vaticano. Mas a maioria das grandes atrações do mundo foi definitivamente retirada do mercado há vários séculos. Dizem que são componentes da nossa herança humana comum. Sabendo que não estavam à venda, a Disney Corporation não tentou comprar Gettysburg e outros campos de batalha da Guerra Civil e da Guerra Revolucionária. Mas tentou obter direitos de concessão exclusivos. O Congresso dos Estados Unidos não permitiria qualquer investida comercial, mesmo por um conglomerado de entretenimento popular e fiável. A cama de George e Martha Washington não está no quarto de hóspedes de um qualquer bilionário. Permanece em Mount Vernon, onde pode vê-la se pagar o valor de entrada de 17 (mais 7 \$ se quiser levar o seu cão para a ver também).

Qualquer atração moderna está envolta numa forte moralidade democrática que sustenta que esta deve ser aberta, acessível e gratuita para todos. Se for cobrado um valor de entrada, este deverá cobrir apenas a manutenção e não resultar em lucros. Por uma questão de política estrita, nos Estados Unidos, os visitantes não pagam para visitar a Casa Branca ou para ver o Sino da Liberdade e outros monumentos nacionais. Todos os anos, alguém propõe que os dez milhões de pessoas que anualmente atravessam a Golden Gate Bridge deveriam pagar um dólar. E todos os anos a proposta é vetada. Ao contrário dos automobilistas, as pessoas que caminham na ponte estão lá como turistas. Vieram vê-la, vivenciá-la e sentir como é estar lá; não estão a usá-la para chegar 
a Marin ou a São Francisco. Pisam a ponte para torná-la parte da sua própria memória, a lembrança de uma experiência que pode potencialmente ser partilhada com milhões de outras pessoas. Para mais de 1.700 pessoas, de acordo com os últimos dados, saltar da ponte foi a sua última memória3. Mesmo que a cobrança de um dólar mantivesse apenas uma pequena fração dos turistas longe da ponte, a estrutura moral do contrato sustenta que este tipo de experiência e memória partilhada deve estar disponível gratuitamente. Assim tem sido apresentado o argumento, e com sucesso, ao longo da última década.

Uma forte moral sugere que todos os que quiserem nunca devem ser impedidos de ver o sorriso da Mona Lisa ou as outras obras-primas no Louvre. Logo, todos os que estão desempregados, professores, estudantes ou menores de 18 anos podem entrar sempre no Louvre gratuitamente. E todos, independentemente do seu estatuto ou condição financeira, podem entrar gratuitamente no primeiro domingo de cada mês. Se eu pagar $250 €$ por uma visita guiada agendada e personalizada ao Louvre, estou a pagar por conveniência, companhia, conversa e champanhe. Mas não estou a pagar para ver a Mona Lisa. Se eu conseguir esperar até ao primeiro domingo, ela é minha gratuitamente.

\section{OS “BENS GRATUITOS” SÃO O SEGREDO DA RENTABILIDADE DO TURISMO MUNDIAL}

Embora a atração em si seja gratuita ou quase gratuita, podem ser necessárias grandes quantidades de dinheiro simplesmente para poder deslocar-se para estar na sua presença. Além disso, a estratificação económica do transporte (primeira classe e classe "turística"), alojamento e refeições assegura que os viajantes abastados possam gastar o que quiserem ao movimentarem-se entre as atrações mundiais que acreditam que "precisam de ver". Uma estadia de cinco noites na suite mais barata do Grand Bretagne Hotel em Atenas custa $3.500 €$, com pequeno-almoço incluído. Depois de chegarem a uma atração, os turistas podem pagar por um acesso melhor, potenciado ou mais conveniente. O facto de poderem pagar e de pagarem "extras" não altera os termos básicos do contrato turístico.

\section{PORQUE É QUE OS PACOTES TURÍSTICOS OFERECEM SEMPRE MAIS DO QUE UMA EXPERIÊNCIA MERAMENTE "TURÍSTICA"}

De longe, a forma mais comum de exploração comercial dos bens gratuitos do turismo é baseada na oferta de uma experiência "especial", sempre considerada como sendo mais especial do que uma experiência meramente turística. Hoje, nas principais atrações, a maneira como a indústria se insere no contrato geralmente funciona da seguinte forma: posso ver o Louvre do lado de fora gratuitamente a qualquer hora do dia e em qualquer dia da semana. Posso entrar no museu e visitar as suas coleções (ou seja, ver de facto a Mona Lisa) gratuitamente, ou por um valor simbólico de $10 €$ se não quiser esperar pelo "domingo gratuito". Se pagar mais $20 €$, posso passar para o início da fila. Se pagar mais $200 €$, posso ter um guia particular que pode fingir ser meu amigo e servir-me champanhe no fim da minha visita.

\footnotetext{
${ }_{3}$ Retirado de https://www.cbsnews.com/news/the-golden-gate-bridge-to-get-a-suicide-net/
} 
Posso fazer uma longa caminhada no Yellowstone National Park, pagando a minha parte por uma taxa de utilização de automóvel de 25 \$ por sete dias. Ou posso pagar vários milhares de dólares por uma "visita cultural" da Tauck do Yellowstone. A brochura bonita da Tauck afirma: "neste momento... podia estar a ouvir-se a pisar a neve debaixo dos seus pés enquanto caminha por um caleidoscópio de pinheiros cheio de raios de sol em Yellowstone". Qual é a diferença entre a sua caminhada em Yellowstone pela qual poderá ter pago entre zero e 25 e a caminhada que faz através de uma visita guiada da Tauck em Yellowstone por 4.690 \$4? Numa visita guiada da Tauck, não tem a opção de escolher o seu caminho ou os seus companheiros, nem a opção de caminhar sozinho ou parar sempre que quiser. Mas, principalmente, não precisa de pensar em frases extravagantes para explicar a si mesmo e aos outros o quão maravilhoso é aquilo que está a vivenciar na sua caminhada. Uma parte importante daquilo que compra à empresa de visitas guiadas é o enquadramento retórico exagerado das suas experiências e das memórias delas. De acordo com testemunhos de clientes na brochura da Tauck, "como vê o mundo importa... Tudo pode ser inesquecível... Sim, foram umas férias... Mas foi mais como uma experiência transformadora. Foi uma experiência emocional, não uma experiência turística... Nunca nos contentamos com o turismo".

É claro que a empresa de pacotes turísticos nunca pedirá que se "contente com o turismo". O contrato turístico moderno não exige que o dinheiro mude de mãos. Não mais hoje do que nos dias de Stendhal. Cada turista, não importa o quão pouco gastou para chegar lá, sente a mesma neve debaixo dos pés e vê o mesmo sol a espreitar por entre os pinheiros. E cada turista sente o mesmo desejo interno na presença da atração: deve significar alguma coisa. A diferença é que os turistas pobres e os turistas forretas precisam de descobrir por si próprios o que pensar sobre a sua experiência. Os turistas ricos pagam a alguém para pensar por eles. A brochura bonita garantiu antecipadamente que conviverão com os seus conterrâneos socioeconómicos e ouvirão comentários "transformadores" específicos sobre o local, adequados ao seu estatuto social e preconceitos. A enorme variedade de custos relativos às diferentes maneiras de lá chegar não altera a solidão e a igualdade essencial dos turistas perante a atração. O caminho pelos pinheiros é totalmente indiferente se as pegadas na neve foram feitas por quem é rico ou pobre, homem ou mulher, homossexual ou heterossexual, negro ou branco, um presidente, um rei, um CEO, um muçulmano, um cristão, um budista, um judeu etc., ad nauseam. E a atração é totalmente indiferente se os turistas caminham, pedem boleia ou imploram para lá chegar, ou se chegam como "convidados" pagantes da "experiência 'cultural' do universo Yellowstone da família de viagens Tauck" (lembrem-se, eles não fazem "visitas guiadas") 5 .

\footnotetext{
${ }_{4}^{4}$ Custo de acordo com o website da Tauck (htpps://www.tauck.com), consultado a 12 de junho de 2016, mas com a indicação de "esgotado".

${ }^{5}$ Retirado de htpps://www.tauck.com
} 


\section{COMERCIALIZAR O CONTRATO}

Dado que a grande maioria das atrações no enorme conjunto global de itinerários turísticos são "bens gratuitos" democráticos, 99,99\% do dinheiro que muda de mãos na "maior indústria do mundo" deve mudar de mãos fora do local. Aqueles que fazem do turismo um negócio devem acrescentar valor à experiência turística central de forma convincente, prometendo aos seus clientes pagantes algo "único", acesso "aos bastidores" da vida "real" da região que visitam, da forma "como é vivida" pelas populações locais. A empresa de turismo também pode alegar ter reduzido a inconveniência de ter de viajar, ao ponto de dizer que "chegar lá é metade da diversão". Quase todas as brochuras usam múltiplas vezes o termo "autêntico" para descrever a qualidade da visita guiada que está a vender. Mesmo antes de os turistas saírem pela sua porta em direção ao aeroporto, a empresa de turismo já lhes forneceu uma linguagem positiva para caracterizar todos os aspetos da experiência que estão prestes a ter.

Uma relação entre o custo das coisas que o turista vê e o que o turista paga pelo valor acrescentado pelo operador turístico pode ser calculado ao analisar atentamente o custo das paragens em qualquer itinerário turístico. Por exemplo, na visita guiada da Tauck mencionada anteriormente, "Treasures of the Aegean" [Tesouros do Mar Egeu], são cobrados $8.290 \$ /$ pessoa. Além disso, é preciso adquirir as passagens aéreas para o ponto de partida da visita em Atenas e para o regresso a partir da última paragem em Istambul. A maioria das atrações detalhadas que Tauck diz aos seus potenciais clientes que vão "vivenciar" no seu "pequeno cruzeiro" que andará de ilha em ilha são totalmente gratuitas (tal como Stendhal) quando o turista chegar até elas, seja através de uma visita guiada da Tauck ou por conta própria. Isso inclui fazer compras no famoso bazar subterrâneo de Istambul, passear por Santorini a contemplar os famosos edifícios com cúpulas azuis, passear na cidade medieval de Rodes, etc. O local mais caro que os turistas da Tauck vão "vivenciar" é a Acrópole de Atenas, onde é cobrado um valor de entrada de $12 €$. O local com acesso controlado mais barato que irão visitar é o Mausoléu de Halicarnasso, onde a entrada custa um euro. Uma pesquisa na internet (5 de julho de 2016) para saber o custo de uma única entrada em cada um dos locais visitados durante a visita guiada "Treasures of the Aegean" contabiliza um total de $60 €$ para todo o itinerário. Isto inclui os locais da Unesco em Micenas (8€), Delos (5€) e o Palácio de Topkapi, em Istambul ( $9 €)$. Resumindo, se eu viajar com a Juliet Flower MacCannell da nossa casa perto de São Francisco para Atenas, se fizermos o cruzeiro "Treasures" e regressarmos de avião de Istambul, o custo total da nossa viagem seria de 21.000 \$, incluindo os quase 200 \$ que contemplam o custo total da nossa entrada em todos os locais que fazem parte do itinerário - ou seja, todos os locais que não são gratuitos.

\section{PORQUe É QUE O TURISMO CRESCE TÃo RAPIDAMENTE}

Economistas e investigadores da área do turismo com uma tendência empirista não contemplaram nem tentaram compreender as diferenças subtis entre o "produto principal" do turista e os outros produtos conhecidos como "bens e serviços de 
consumo". É a natureza imaginária, omnipresente e polimórfica do principal produto do turismo que torna possível o rápido crescimento da sua indústria. Os economistas deveriam ter percebido que algo está radicalmente errado com as suas suposições quando classificaram os dólares do turista como receitas de "exportações".

Os turistas estrangeiros do lado do recibo são considerados "exportações". Por outras palavras, os recibos de moeda são considerados excedentes. Os turistas nacionais que viajam para o estrangeiro são considerados "importações"... e colocados no lado do débito do livro razão (Sessa, 1983, p. 133).

A designação faz sentido na medida em que o turismo gera divisas, da mesma forma que a venda de produtos no estrangeiro as gera. Mas todas as semelhanças terminam com a cor do dinheiro recebido. Nada de valor foi "exportado"; os turistas foram "importados". A Grécia moderna não se deu ao trabalho de fabricar Delfos e de a enviar para o estrangeiro para ser vendida aos consumidores (embora possa ser argumentado que algo deste género ocorreu com o infame caso dos chamados "Mármores de Elgin"). Nada tangível sai da Grécia onde é revendido, usado até ficar desgastado, esmagado e reciclado. A turista paga para viajar até Delfos. Depois de a vivenciar, deixa-a para trás para que outros turistas possam vir e ver. Delfos, o Partenon, o Édipo, os edifícios de cúpulas azuis e as praias de Santorini são o principal fator motivador de todas as transações económicas necessárias para a presença de turistas, mas as atrações em si não são "consumidas". Estas continuam a transcender as leis económicas de produção e consumo, independentes e inconscientes das maquinações que colocam milhões de turistas na sua presença.

O tamanho e o crescimento atual da economia turística marcam o início do fim das relações económicas, conforme descrito por Marx e totalmente operacionalizado sob o capitalismo tardio. Os mercados globais baseados na capacidade de calcular equivalências monetárias entre unidades de trabalho e o valor dos bens materiais produzidos pela mão de obra não são sustentáveis. Os produtos eletrónicos pessoais e os produtos farmacêuticos são as únicas indústrias globalmente importantes que se baseiam em produtos que exigem extração e processamento patenteados de recursos naturais, reengenharia ou reformulação periódica para permanecerem competitivas, fábricas criadas especificamente para esse fim, embalagens especializadas, transporte mundial através de camiões, comboios, navios porta-contentores ou petroleiros, redes coordenadas de grossistas, publicidade, pontos de venda a retalho e serviço pós-consumo especializado, incluindo suporte técnico e reciclagem. Mas os produtos farmacêuticos e eletrónicos não se aproximam do impacto económico global do turismo. O crescimento futuro provavelmente será modelado no turismo e nas partes da internet onde os consumidores também se tornam o produto.

O turismo é o prenúncio de uma revolução económica baseada num tipo de "produto" inteiramente novo. O que é comprado nada mais é do que uma configuração de imagens e símbolos na consciência e no discurso humano. Este novo produto não possui qualquer materialidade. Existe apenas na mente humana e na linguagem. Ninguém compreende o desejo por este novo produto, apenas que é poderoso e quase universal. Este desejo põe o materialismo dialético do avesso. Com poucas (às vezes zero) 
solicitações, a própria consumidora assume o design do produto e a sua reformulação periódica. A consumidora transporta-se para a representação material dos seus desejos. A consumidora assume tanta responsabilidade pela logística da sua conceção, fabrico e distribuição que ela mesma se assemelha cada vez mais a um dos produtos do capitalismo materialista à moda antiga. Agora, uma vasta rede horizontal de serviços existente e desarticulada move estes consumidores-enquanto-produtos ao longo de uma linha de montagem global, essencialmente ao ar livre. Nenhum negócio é muito pequeno ou muito fora de mão que não possa contribuir. Um quiosque que venda um par de óculos de sol ou uma bomba de gasolina que venda um depósito cheio de combustível, um mapa e um refrigerante fresco pode dar um contributo importante ao produto acabado. A montagem não requer a coordenação de tecnologias complexas. A montagem final é exatamente isso, por exemplo, multidões de turistas "montados" na ilha de Santorini, na praia de Oia, para ver o pôr do sol.

Os custos iniciais para empresas turísticas nunca incluem o custo da atração. Qualquer pessoa pode disponibilizar um quarto para visitantes no Airbnb e mantê-lo ocupado todas as noites, uma vez que fica a uma curta distância do museu de arte da cidade. Não foi preciso comprar, acomodar e proteger as obras de arte do museu para alugar o seu quarto. Os únicos perigos para a atração e para aqueles cujos negócios dependem disso são representados pela sua popularidade. Um risco constante para uma atração e o seu ambiente circundante é o seu sucesso. Um grande número de turistas pode danificá-la involuntariamente devido à sua proximidade contaminadora, respirando sobre ela ou deixando lá lixo ou tornar-se ela própria irritante e uma distração para os seus anfitriões locais e, mais importante, para outros turistas. O Sino da Liberdade teve de ser retirado do Independence Hall, em Filadélfia, porque a vibração dos passos dos visitantes estava a ameaçar a integridade estrutural do salão, quase tão preciosa e famosa quanto o Sino que outrora continha.

Em comparação com outros recursos denominados "sustentáveis", porém, as atrações turísticas parecem ser nada menos que milagrosas. Diz-se que os produtos de madeira são sustentáveis porque as florestas abatidas podem ser replantadas e crescer novamente. Imagine uma floresta mágica que cresce em menos de um piscar de olhos depois de ser abatida, com todas as árvores ainda mais maduras do que eram no momento anterior. É essa a essência da atração enquanto recurso. Cada visita serve apenas para melhorar a reputação e o desejo da atração. As visitas ao famoso pôr do sol de Oia não envolvem usá-lo como um recurso finito, para que desapareça lentamente. O pôr do sol e os turistas voltam seguramente noite após noite. Cada "utilização" do pôr do sol apenas potencia o seu poder e fama, e contribui para a sua "produção" futura.

\section{A ADAPTAÇÃO DO TURISMO A ESQUEMAS ECONÓMICOS NEOLIBERAIS}

Turismo, lazer e viagens são os setores de maior crescimento e rentabilidade na economia mundial, devido à sua fácil adaptabilidade a esquemas económicos neoliberais que procuram transformar todos os aspetos da existência humana num produto. Conforme sugerido na secção anterior, a única ameaça real ao modelo de negócio do 
turismo genérico é o seu próprio sucesso. Ou seja, demasiados turistas a estragar a experiência do turista. O turismo mundial está a começar a ficar fora de controlo, destruindo a qualidade de vida e a qualidade das experiências turísticas nos locais que os turistas mais desejam visitar.

Mas o crescimento do turismo não é apenas uma questão de exploração excessiva do sistema global existente de atrações gratuitas: por exemplo, enfiar milhares de pessoas em gigantescos navios de cruzeiro, cobrando-lhes umas férias "tudo incluído" e despejando-as em Veneza, onde não pagam qualquer taxa de entrada e arrasam com a Piazza San Marco. Davis e Marvin (2004) facultaram um excelente estudo do caso de overtourism em Veneza. Além do auto-cancelamento do turismo estabelecido, existe uma crença quase universal nos poderes mágicos transformativos do turismo; que o turismo é o caminho mais rápido para salvar economias regionais fracassadas ou com baixo desempenho.

Se o setor da indústria de uma região falhar, ou se o seu setor agrícola permanecer preso a práticas de produção centenárias, o turismo poderá ajudar. Qualquer coisa e nada num cenário local pode ser reformulado para consumo turístico. Um local subdesenvolvido, sem amenidades, pode ser vendido como "puro" e "intocado". Um lugar que é invadido por turistas pode ser vendido como "popular" ou de "paragem obrigatória".

Um agricultor tem a opção de recusar comprar equipamentos modernos e de pagar aos seus trabalhadores um salário digno. Situada numa região pitoresca, uma quinta precisa apenas da impressão rápida de uma brochura bonita e de uma página web para atrair turistas que pagam ao agricultor para fazerem a colheita, usando métodos tradicionais ("sustentáveis"). Se a cozinha da quinta ainda tiver um fogão a lenha, os hóspedes vão pagar para cozinhar as suas próprias refeições como parte de uma experiência rural tradicional "autêntica".

Se uma região industrial caiu em ruína económica e física, mais uma vez, é o turismo que a vai resgatar. Lena Tegtmeyer (2016) deu-nos um excelente estudo de caso de Detroit, que se tornou um local de peregrinação para turistas que vêm testemunhar as ruínas do capitalismo industrial. Como muitas vezes acontece, a Detroit pós-apocalíptica foi inicialmente descoberta por artistas, fotógrafos, exploradores, estudantes pobres que não tinham dinheiro para pagar atrações comercializadas e hipsters bem vestidos à procura de algo exótico. Foi apenas nessa altura, de acordo com Tegtmeyer, que o Detroit Tourist Bureau (Gabinete de Turismo de Detroit) e os promotores turísticos começaram a perceber o fascínio das linhas de montagem enferrujadas e degradadas das antigas fábricas de automóveis abandonadas. O ponto principal de Tegtmeyer é que o turismo de ruínas tem o poder de reformular evidências físicas de "falhas" económicas desastrosas numa economia (turística) de serviços de "sucesso". À medida que as economias neoliberais compreendem e controlam de forma crescente o turismo, e tentam moldar os seus fundamentos ideológicos, ampliam exponencialmente a sua capacidade de ganhar dinheiro com qualquer coisa, até mesmo com condições económicas negativas, até mesmo com nada.

As companhias aéreas descobriram como cobrar aos seus clientes o dobro ou mais por não usarem os seus serviços. Como é que isto funciona? Uma passageira 
reserva e paga um voo com três escalas, por exemplo, São Francisco, Amsterdão, Paris, São Francisco. À sua chegada a Amsterdão, alguém lhe oferece uma boleia para Paris e decide que prefere viajar de carro com um amigo em vez de voar. Caso não tenha lido as letras pequenas do seu contrato de reserva com a companhia aérea, ficará chocada ao descobrir que o seu bilhete de volta de Paris para São Francisco foi cancelado quando não embarcou no voo de Amsterdão para Paris. "Desculpe, não é possível proceder ao reembolso. Terá de pagar novamente essa parte da sua viagem". Então, deixou o seu lugar de Amsterdão para Paris vazio, para que a companhia aérea o possa revender a um passageiro em lista de espera. E tem de pagar o dobro pelo voo de Paris para São Francisco. Ou, caso tivesse lido as letras pequenas, saberia que devia contactar a companhia aérea para cancelar a passagem de Amsterdão para Paris. Caso ligue, pode impedir que o seu regresso a São Francisco seja anulado pela companhia aérea. Mas não receberá o reembolso pela passagem não utilizada. E haverá também uma taxa de cancelamento adicional de 300 \$. A companhia aérea fica com a tarifa original na sua totalidade, mais 300 \$ e consegue vender o seu lugar a outro cliente. A companhia aérea aumenta o seu lucro por ela não ter voado de Amsterdão para Paris em várias centenas de pontos percentuais sobre o que teria sido se ela realmente tivesse apanhado o voo. Nem todas as linhas aéreas adotam esta prática, mas sei por experiência pessoal que muitas o fazem.

\section{OVERTOURISM}

O overtourism (excesso de turismo) surgiu nos últimos anos como uma consciencialização por parte das comunidades anfitriãs de que o turismo pode tornar-se uma coisa demasiado boa. Alguns destinos estão a ficar sobrelotados com turistas, levando as instituições e amenidades locais ao ponto de rutura e tornando a vida insuportável para a população local. Assim que os contornos básicos do contrato turístico moderno são claros, deve ser relativamente fácil perceber as causas do overtourism e abordar as soluções.

O contrato turístico moderno não é, por si só, a fonte do overtourism. São as muitas formas como os voos fretados, navios de cruzeiro, autocarros gigantes cheios de turistas com pacotes, cadeias de resorts, etc. exploram o contrato, que leva à sobrelotação de lugares como a Costa del Sol em Espanha e Veneza. Fodor's pode duplicar o número de visitantes que leva até à Mona Lisa sem pintar outra Mona Lisa. Freddy Laker pode quintuplicar o número de visitantes que deixa numa praia espanhola sem fabricar mais praia. A indústria pode aumentar exponencialmente o número de turistas que comprime numa região sem contribuir com nada para manter a atração, para além das taxas de entrada simbólicas.

Mas não é apenas a exploração implacável do sistema global de atração enquanto "bens gratuitos" que causa o overtourism. A monetização bem-sucedida da experiência turística envolve a retenção da forma do contrato original e a eliminação da sua substância. A indústria incentiva o frenesim de viajar até aos lugares como a essência do turismo. Há pouco interesse da indústria no turista que quer ir à Grécia para ver Delfos. O contrato turístico, motivado por uma curiosidade específica, tem muitas opções e pode comprar serviços de viagem. A principal motivação do setor é moldar e controlar o 
turismo, reduzindo a importância da especificidade do local na seleção de um destino. O turista ideal, do ponto de vista da indústria, é alguém que responde: "ok, parece-me bem" à oferta "aqui está o itinerário que selecionámos para si dentro do seu orçamento, em tudo incluído". Essencialmente, o que este turista vivenciará serão os seus companheiros de viagem que também desempenham valentemente $o$ ato de ser turista.

Tudo isto foi bem compreendido por Walt Disney quando concebeu as primeiras atrações substitutas: "It's a Small World", "Rivers of the World" , "Mainstreet U.S.A." e "Matterhorn", diversões na Disneylândia original. Todas sugerem a possibilidade de ter uma experiência quase turística. A mesma estratégia é utilizada pelos proprietários de casinos em Las Vegas que construíram réplicas da Estátua da Liberdade, da Torre Eiffel, da Golden Gate Bridge, dos canais de Veneza, da tumba do Rei Tut, etc., nos seus estabelecimentos de jogo. Os casinos seguem assiduamente a fórmula do contrato, mesmo sabendo que não está em sintonia com o seu modelo básico de negócio. Ou seja, não cobram nada aos seus visitantes para ver as suas atrações replicadas. Os dólares dos turistas são gastos ali ao lado, nas mesas de jogo.

Num estudo recente de 17 operadores turísticos escandinavos (Wall-Reinius, Ioannides e Zampoukos, 2019), os autores descobriram que o destino não importa, ou importa muito pouco, quer na produção quer no consumo de viagens "em tudo incluído". O que é importante para os clientes é o preço, o facto de ser "tudo incluído", para que não haja despesas surpresa e o facto de que vão efetivamente para algum sítio, mas onde exatamente não é importante. Os clientes quase não exprimem interesse no destino específico. Wall-Reinius et al. (2019) consideram que "tudo incluído" é mais lucrativo para os operadores, é mais flexível, pois o destino pode ser alterado sem modificar a experiência ou a forma como é comercializado, e é desejado por uma classe crescente de clientes que quer minimizar despesas e riscos inesperados durante as férias. Os clientes deste tipo de viagem querem essencialmente reduzir o inesperado para quase zero.

Há uma diferença clara entre os turistas "tudo incluído" e os "turistas do contrato", precisamente motivados por um conjunto de desejos opostos; que desejam o inesperado, que exigem um contacto direto com a "alteridade" específica do local e estão dispostos a suportar inúmeras despesas e dificuldades para se colocarem na presença física dos objetos dos seus desejos turísticos. Isto levanta a questão de saber se o tipo de contrato turístico em que "o lugar importa" é a mesma ordem de experiência humana que o turismo onde a "geografia não importa".

Cruzeiros, parques temáticos e resorts de férias isolados oferecem uma grande variedade de lazer, relaxamento, entretenimento, mimos e socialização em ambientes fechados. Não expõem o turista à diferença, mas mimam-no com aquilo que é socialmente familiar. Estes e outros pacotes de lazer anti-iluminismo são geralmente baseados na repetição formalista das características acidentais e superficiais do turismo e já não estão ligados ao contrato turístico moderno, aos ideais democráticos ou à curiosidade. Um exemplo sintomático seriam "cruzeiros para lugar nenhum". O navio sai do porto, segue sete milhas mar adentro, ancora por cinco ou sete dias, serve comida, bebidas, jogos, oportunidades de compras, dança e outros entretenimentos, depois volta ao porto para reabastecer para a próxima leva. 
O desejo de fazer um cruzeiro para lugar nenhum é diametralmente oposto ao que animava a curiosidade e as observações do Sr. $\mathrm{L}$ de Stendhal. Aos turistas de cruzeiro (aqueles que realmente vão a algum lugar) são oferecidas viagens paralelas às atrações locais do contrato nos portos de escala. E qualquer grande atração que possam ver, mesmo de longe, provavelmente figurará nas suas contas pré e pós-viagem. Mas a oportunidade de um contacto ocasional com atrações do contrato não precisa de ser o principal motivo para fazer um cruzeiro. A ênfase nas descrições do cruzeiro "Treasures of the Aegean" de 14 dias da Tauck Tours é o cocktail de abertura no Grande Bretagne Hotel em Atenas e a socialização com outros turistas de cruzeiro; "jogar jogos de tabuleiro no convés", "ou apenas relaxar na banheira de hidromassagem do navio"6.

Pelo menos, o cruzeiro para lugar nenhum não atrapalha a vida da população local. Outros pacotes que são indiferentes aos lugares que visitam acrescentam insulto à injúria. Ninguém quer ser atropelado por milhares de turistas que não se importam onde estão, que estariam igualmente felizes a destruir a qualidade de vida de qualquer outro lugar.

Existem várias soluções possíveis para o overtourism. Antes de serem consideradas, é útil perceber que o contrato turístico moderno democrático, o turismo que Stendhal descreveu pela primeira vez, não desaparecerá. Nem resultará na maioria dos lugares ficarem sobrelotados com turistas. Mesmo que a indústria não reunisse e entregasse um grande número de turistas, todos os lugares do mundo continuarão a ser visitados por interessados e curiosos o suficiente para ir até lá e motivados o suficiente para encontrar o caminho. Na década de 1980, os meus filhos pequenos ficaram a ver os créditos finais de um filme que adoraram para saber onde é que ele tinha sido rodado. Quando visitámos a Escócia pouco depois, insistiram que eu os levasse até à remota vila montanhosa mencionada nos créditos. Enquanto desfrutávamos de chá e scones na esplanada do café, perguntei à jovem empregada se isto era "onde o filme Momento inesquecível foi filmado". Ela sorriu e respondeu com um leve sotaque escocês: "claro, mas é o primeiro a perguntar-nos isso". Sem o transporte em massa de turistas por parte da indústria e a entrada forçada de turistas em destinos de "visita obrigatória", todos os lugares do mundo receberiam exatamente o tipo e o número de turistas que merecem.

Existem soluções diretas para o problema do overtourism. Restaurantes locais, pensões, etc. poderiam coletiva e sistematicamente aumentar as suas tarifas para manter os níveis de lucro e reduzir o número de pessoas atendidas, até ser alcançado um "ponto ideal" tolerável. Governos a todos os níveis poderiam impor impostos sobre desembarques de voos fretados, ancoragem de navios de cruzeiro e estacionamento de autocarros turísticos. Os impostos poderiam ser aumentados até o número de chegadas baixar para níveis aceitáveis. As receitas dos impostos poderiam ser usadas para melhorar as perdas económicas do setor do turismo local. Os departamentos de polícia local poderiam aplicar rigorosamente as leis relativas a lixo, desordem, embriaguez pública, drogas, barulho e comportamento lascivo em turistas que acreditam que "fugir de tudo" significa eliminar todas as obrigações sociais. Existem inúmeras ferramentas para reduzir os impactos do overtourism, se este for realmente considerado um problema sério. Mas essa é uma discussão para outro artigo.

\footnotetext{
${ }^{6}$ Retirado de htpps://www.tauck.com
} 
Em conclusão: sempre houve turismo. E sempre haverá. Não precisa é de ser um hiper-turismo que reflita as características da superfície, mas não a substância do contrato turístico moderno democrático.

Tradução: A Inovtrad - Tradução, Formação e Serviços, Unipessoal, Lda.

\section{Agradecimentos}

Este trabalho é financiado por fundos nacionais através da FCT - Fundação para a Ciência e a Tecnologia, I.P., no âmbito do projeto UIDB/00736/2020. O Financiamento Plurianual do Centro de Estudos de Comunicação e Sociedade (UIDB/00736/2020) apoiou a tradução do artigo para português.

\section{REFERÊNCIAS}

Davis, R. C. \& Marvin, G. R. (2004). Venice: the tourist maze. Berkeley: University of California Press.

Fisher, R. (2012). Fodor's greece. Nova lorque: Random House.

MacCannell, D. (2011). The ethics of sightseeing. Berkeley: University of California.

Seferis, G. (1997). Delphi. In A. Leonites (Ed.), Greece: a traveler's literary companion (pp. 84-99). Berkeley: Whereabouts.

Sessa, A. (1983). Elements of tourism economics. Roma: Catal.

Stendhal (1962). Memoirs of a tourist. Evanston: Northwestern University Press.

Tegtmeyer, L. (2016). Tourism aesthetics in ruinscapes: bargaining cultural and monetary values of Detroit's negative image. Tourist Studies, 16(4), 462-477. https://doi.org/10.1177/1468797615618100

Wall-Reinius, S., loannides, D. \& Zampoukos, K. (2019). Does geography matter in all-Inclusive resort tourism? Marketing approaches of Scandinavian tour operators. Tourism Geographies, 21(5), 766-784. https://doi.org/10.1080/14616688.2017.1375975

\section{NOTA BIOGRÁFICA}

Dean MacCannell é Professor Emérito de Design Ambiental da Universidade da Califórnia em Davis. É o autor de The tourist: a new theory of the leisure class (1976, 2013); Empty meeting grounds - the tourist papers (1992), The Ethics of sightseeing (2012) e vários outros livros e artigos que analisam as formas culturais emergentes da globalização.

ORCID: https://orcid.org/oooo-0003-3119-4453

Email: edmaccannell@ucdavis.edu

Morada: University of California, Davis, One Shields Avenue, Davis, CA 95616 | 530-752-1011

\section{Submetido: 06/09/2019}

Aceite: 31/11/2019 